\title{
MÉTODOS PARA SUPERAÇÃO DA DORMÊNCIA E BIOMETRIA DE FRUTOS E SEMENTES DE Parkia nitida MIQUEL. (LEGUMINOSAE - MIMOSOIDEAE)
}

\author{
Eniel David CRUZ', José Edmar Urano de CARVALHO', \\ Noemi Vianna Martins LEÃO'
}

RESUMO-Foram realizadas avaliaçōes biométricas em frutos e sementes de Parkia nitida e estudado o efeito dos tratamentos escarificação mecânica sem $\left(\mathrm{T}_{2}\right)$ e $\operatorname{com}\left(\mathrm{T}_{3}\right)$ aplicação do fungicida Benomyl; imersão em $\mathrm{H}_{2} \mathrm{O}$ a $80^{\circ} \mathrm{C}\left(\mathrm{T}_{4}\right)$ e a $100^{\circ} \mathrm{C}\left(\mathrm{T}_{5}\right)$; imersão em $\mathrm{H}_{2} \mathrm{SO}_{4}$ durante $10\left(\mathrm{~T}_{6}\right), 20\left(\mathrm{~T}_{7}\right), 40\left(\mathrm{~T}_{8}\right)$ e $80\left(\mathrm{~T}_{4}\right)$ minutos, na superação da dormência das sementes. Foram totalizadas as sementes germinadas aos $10,20,30$ e 40 dias após a semeadura. $\mathrm{O}$ ensaio foi instalado com quatro repetiçōes de 50 sementes, semeadas em substrato de vermiculita. O número de frutos/inflorescência variou de um a oito. $\mathrm{O}$ comprimento e largura dos frutos e o número de sementes/fruto variaram de 36,0 a $80,0 \mathrm{~cm}$, de 4,6 a $6,5 \mathrm{~cm}$ e de 17 a 37 sementes, respectivamente. $\mathrm{O}$ comprimento, a largura e a espessura das sementes variaram de 16,1 a $24,0 \mathrm{~mm}$, de 8,1 a $14,0 \mathrm{~mm}$ e de 5,1 a $9,0 \mathrm{~mm}$, respectivamente. Houve interação significativa entre métodos para superação da dormência e dias decorridos após a semeadura na germinação das sementes. As análises de regressão mostraram significância para os tratamentos $\mathrm{T}_{2}, \mathrm{~T}_{3}, \mathrm{~T}_{4}, \mathrm{~T}_{6} \mathrm{eT}_{8^{\circ}} \mathrm{OT}_{4}$ proporcionou apenas 10,0\% de germinação; entretanto os tratamentos $\mathrm{T}_{2}$ e $\mathrm{T}_{3}$ tiveram efeito satisfatório, com $50,0 \%$ e $72,5 \%$ de germinação, respectivamente. Os tratamentos com $\mathrm{H}_{2} \mathrm{SO}_{4}$ estiveram entre os mais eficientes, com $80,0 \%$, $82,5 \%, 80,5 \%$ e $74,5 \%$, durante $10,20,40$ e 80 minutos de imersão, respectivamente. As percentagens de germinação para o $\mathrm{T}_{1}$ (testemunha) e $\mathrm{T}_{5}$ foram inferiores a 2,5\%. Concluiu-se que sementes de $P$. nitida apresentam dormência devido à impermeabilidade do tegumento à água; é necessária a escarificação das sementes para se obter elevada percentagem de germinação; tratamentos com $\mathrm{H}_{2} \mathrm{SO}_{4}$, por 20 minutos, e escarificação mecânica + fungicida constituem-se métodos eficientes para superação da dormência.

Palavras-chave: leguminosa, semente, dormência, germinação.

\section{Methods for Overcoming Dormancy and Fruit and Seed Biometry in Parkia nitida Miquel. (Leguminosae - Mimosoideae)}

SUMMARY - The biometry of fruits and seeds of Parkia nitida was studied, as were the effects of mechanical escarification without $\left(\mathrm{T}_{2}\right)$ and with $\left(\mathrm{T}_{3}\right)$ Benomyl fungicide, immersion of seeds in hot water at $80^{\circ} \mathrm{C}\left(\mathrm{T}_{4}\right)$ and at $100^{\circ} \mathrm{C}\left(\mathrm{T}_{5}\right)$, and immersion in $\mathrm{H}_{2} \mathrm{SO}_{4}$ during $10\left(\mathrm{~T}_{6}\right), 20\left(\mathrm{~T}_{7}\right), 40\left(\mathrm{~T}_{8}\right)$ and $80\left(\mathrm{~T}_{9}\right)$ minutes. Treatment effects were evaluated by counting total germinated seeds at 10,20,30 and 40 days after sowing. The experiment was established with four replications of 50 seeds, which were sown in vermiculite. The number of fruits per inflorecense varied from one to eight. The length and width of fruits and the number of seeds per fruits ranged from 36.0 to $80.0 \mathrm{~cm}, 4.6$ to $6.5 \mathrm{~cm}$ and 17 to 37 seeds, respectively. The length, width and thickness of seeds ranged from 16.1 to $24.0 \mathrm{~mm}, 8.1$ to $14.0 \mathrm{~mm}$ and 5.1 to $9.0 \mathrm{~mm}$, respectively. There was a significant interaction between scarification methods and period required for seeds to germinate. Regression analysis was significant for $\mathrm{T}_{2}, \mathrm{~T}_{3}, \mathrm{~T}_{4}, \mathrm{~T}_{6}$ and $\mathrm{T}_{8}$. Germination under $\mathrm{T}_{4}$ was only $10 \%$, but $\mathrm{T}_{2}$ and $\mathrm{T}_{3}$ had satisfactory effects on seed germination $(50.0 \%$ and $72.5 \%$, respectively). The treatments with $\mathrm{H}_{2} \mathrm{SO}_{4}$ were the most efficient, with mean germination of $80.0 \%, 82.5 \%$, $80.0 \%$ and $74,5 \%$ for $10,20,40$ and 80 minutes of immersion, respectively. Germination of seeds subjected to $\mathrm{T}_{1}$ (control) and $\mathrm{T}_{5}$ was lower than $2.5 \%$. It was concluded that seeds of $P$. nitida have dormancy caused by integument impermeability; it is necessary to treat the seeds to obtain high germination percentage. Treatments using $\mathrm{H}_{2} \mathrm{SO}_{4}$ for 20 minutes and mechanical escarification of seed treated with fungicide were the best for breaking dormancy.

Key-words: legume, seed, dormancy, germination.

'Pesquisadores da Embrapa Amazônia Oriental, Caixa Postal 48, CEP 66017-970, Belém, PA, Brasil. E-mail: eniel@cpatu.embrapa.br. 


\section{INTRODUÇÃO}

O gênero Parkia é encontrado principalmente em floresta tropical úmida, onde existem cerca de 17 espécies, que ocorrem em áreas de floresta de terra firme, várzea sazonal e floresta secundária (Hopkins, 1986). Dessas espécies, $P$. multijuga, $P$. nitida $=$ P. oppositifolia, $P$. paraensis, $P$. pendula e $P$. ulei são conhecidas como fornecedoras de madeiras comerciais na Amazônia (IBDF, 1987).

A caracterização biométrica de frutos e sementes pode fornecer subsidios importantes para diferenciação de espécies do mesmo gênero. Carpanezzi \& Marques (1981) observaram que o peso das sementes de Hymenaea courbaril é quase duas vezes superior ao peso das sementes de Hymenaea parvifolia. O conhecimento da biometria das sementes também é importante para se ter idéia do esforço reprodutivo da planta (Fenner, 1993), e para diferenciar espécies pioneiras e não pioneiras em florestas tropicais (Baskin \& Baskin, 1998).

Estudos realizados por Alencar \& Magalhães (1979), sobre a germinação de doze espécies florestais da Amazônia, permitiram classificálas em três grupos: espécies que apresentaram boa germinação em curto espaço de tempo; espécies que apresentaram boa germinação, porém necessitam de um período longo para germinarem; e, espécies com baixa germinação e longo período para germinarem. Knowles \& Parrotta (1995) estudaram a germinação em
160 espécies de floresta nativa na região de rio Trombetas, Pará, e observaram que $28 \%$ das espécies requerem escarificação mecânica ou tratamento químico, para quebra de dormência.

Em leguminosas tropicais, a impermeabilidade do tegumento da semente à água é o mecanismo mais comum de dormência (Rolston, 1978), ocorrendo com mais freqüência nas subfamílias Caesalpinioideae e Mimosoideae (Duarte, 1978). A percentagem deste tipo de semente em leguminosas pode atingir até $98 \%$, conforme observaram Cruz et al. (1997) em Centrosema pubescens. Para a superação da dormência nessas sementes, vários tratamentos têm se mostrado eficientes. Em espécies do gênero Parkia, sementes tratadas com ácido sulfúrico, escarificação manual em superfície abrasiva, desponte no tegumento e água quente geralmente apresentam índices elevados de germinação (Etejere et al., 1982; Barbosa et al., 1984; Varela et al., 1986/1987).

Este trabalho objetivou determinar as caracteristicas biométricas e identificar tratamentos pré-germinativos para promover a germinação de sementes de $P$. nitida $=$ P. oppositifolia.

\section{MATERIAL E MÉTODOS}

\section{Local de coleta e de avaliação}

As sementes foram coletadas de três árvores, em floresta nativa, no municipio de Paragominas, Pará 
(02 ${ }^{\circ} 40^{\prime} 56^{\prime \prime} \mathrm{S}$ e $\left.46^{\circ} 49^{\prime} 59^{\prime \prime} \mathrm{O}\right)$. O ensaio foi conduzido no Laboratório de Sementes de Espécies Florestais, da Embrapa Amazônia Oriental, em Belém, Pará.

\section{Biometria de frutos e sementes}

Foram determinados o número de frutos por inflorescência, em 82 inflorescências; comprimento e largura dos frutos e número de sementes por fruto, em 94 frutos; comprimento, largura e espessura das sementes, em 100 sementes; volume e peso de 1.000 sementes, em quatro repetições de 1.000 sementes; e percentagem de sementes danificadas por insetos, em quatro repetições de 100 sementes. A determinação do grau de umidade das sementes foi realizada em quatro repetições de dez sementes, adotando-se o método da estufa a $105 \pm 3^{\circ} \mathrm{C}$, durante 24 horas, conforme Brasil (1992)

\section{Tratamentos para superação da dormência}

As sementes foram submetidas a tratamentos para superação da dormência, sendo utilizados os tratamentos: testemunha (sementes não tratadas); escarificação mecânica em esmeril elétrico na porção terminal da semente, sem aplicação de fungicida; escarificação mecânica em esmeril elétrico na porção terminal da semente, com aplicação de fungicida (Benomyl a $0,1 \%$ ); imersão em água a $80^{\circ} \mathrm{C}$ e $100^{\circ} \mathrm{C}$ desligando-se em seguida a fonte de calor, permanecendo as sementes imersas na água durante quatro horas; $\mathrm{e}$ imersão em ácido sulfúrico $\mathrm{PA}$, durante $10,20,40$ e 80 minutos. As sementes germinadas foram quantificadas diariamente e os totais computados aos 10,20,30 e 40 dias após a semeadura. Também foram computadas, no final do experimento, as percentagens de sementes duras e mortas e a percentagem de plântulas anormais, de acordo com Brasil (1992).

\section{Delineamento experimental e análise estatística}

O ensaio foi conduzido em delineamento inteiramente casualizado, com quatro repetições de 50 sementes. As sementes foram semeadas em substrato de vermiculita e os testes de germinação conduzidos nas condições ambientais locais $\left(26,6^{\circ} \mathrm{C}\right.$ de temperatura média). Os dados obtidos inicialmente foram submetidos ao teste de Bartlett, para se verificar a homogeneidade das variâncias (Zar, 1996), sendo necessária a transformação dos dados de percentagem de germinação e de sementes duras. A transformação utilizada foi arcoseno $\sqrt{x+0,5 / 100}$ conforme sugere Ahrens et al. (1990). Para as variáveis biométricas foram realizadas distribuições de freqüências e construidos histogramas. Para a variável percentagem de germinação foram realizadas análises de variância, sendo estudado o efeito dos métodos para superação da dormência e a interação (método para superação da dormência $x$ dias decorridos após a semeadura), e de regressão. Também foram realizadas análises de variância 
para as percentagens de sementes duras e mortas e percentagens de plântulas anormais, sendo os tratamentos com média zero excluidos das análises, conforme sugere Finney (1989). Os gráficos das regressões e os testes de médias são apresentados com dados destransformados. As análises de variância e de regressão foram realizadas com o software Minitab (Minitab, 1993) e o ajuste das equações de regressão com o software Statistica (Statsoft, 1994).

\section{RESULTADOS E DISCUSSÂO}

\section{Biometria de frutos e sementes}

A maioria das inflorescências $(58,5 \%)$ apresenta de três a quatro frutos, com limites mínimo e máximo de um e oito frutos por inflorescência (Fig. 1A). O comprimento dos frutos variou de 36,0 a $80,0 \mathrm{~cm}$, sendo que $47,8 \%$ mediram de 61,0 a $70,0 \mathrm{~cm}$ (Fig. 1B). Corrêa (1926) e Hopkins (1986) afirmam que frutos de $P$. nitida medem cerca de $30 \mathrm{~cm}$, valor inferior ao observado em todos os frutos avaliados. A largura dos frutos apresentou pouca variação (Fig. 1C), com $56 \%$ deles na faixa de 5,1 a 5,5 $\mathrm{cm}$. Por outro lado, o número de sementes por fruto foi bastante variável, com a maioria dos frutos contendo de 29 a 34 sementes (Fig. 1D). As sementes de $P$. nitida são oblongas, com comprimento, largura e espessura variando de 16,1 a 24,0 $\mathrm{mm}$, de 8,1 a $14,0 \mathrm{~mm}$ e de 5,1 a 9,0 $\mathrm{mm}$, respectivamente. Porém, predominou sementes com comprimento entre 19,1 e $21,0 \mathrm{~mm}$, largura entre 10,1 e $12,0 \mathrm{~mm}$ e espessura entre 6,1 e 7,0 mm (Figs 2A, $\mathrm{B}, \mathrm{C}$, respectivamente). $\mathrm{O}$ volume e o peso de 1.000 sementes, com 10,3\% de umidade, apresentaram valores de $1.344,0 \mathrm{~cm}^{3}$ e de $989,5 \mathrm{~g}$, respectivamente.

A percentagem de sementes infestadas por insetos, identificados como sendo da ordem coleóptera, foi alta $(32,5 \%)$. Os danos ocasionados foram perfurações abundantes no tegumento, atingindo tecidos cotiledonares. Esses danos foram constatados imediatamente após a colheita.

\section{Tratamentos para superação da dormência.}

As sementes de $P$. nitida apresentam germinação epígea e a plântula é do tipo fanerocotiledonar. A análise de variância da percentagem de germinação apresentou interação significativa entre métodos para superação da dormência e dias decorridos após a semeadura. As análises de regressão mostraram significância apenas para os tratamentos escarificação mecânica em esmeril elétrico na porção terminal da semente sem e com aplicação de fungicida, imersão em água a $80^{\circ} \mathrm{C}$ e imersão em ácido sulfúrico concentrado durante 10 e 40 minutos.

A imersão em água a $80^{\circ} \mathrm{C}$ e a $100^{\circ} \mathrm{C}$ apresentaram pouca eficiência na superação da dormência, proporcionando $10,0 \%$ e 2,5\% de germinação aos 40 dias, respectivamente. Ressalte-se que essa baixa percentagem de germinação foi decorrente do fato de que $70 \%$ e $64 \%$ das 

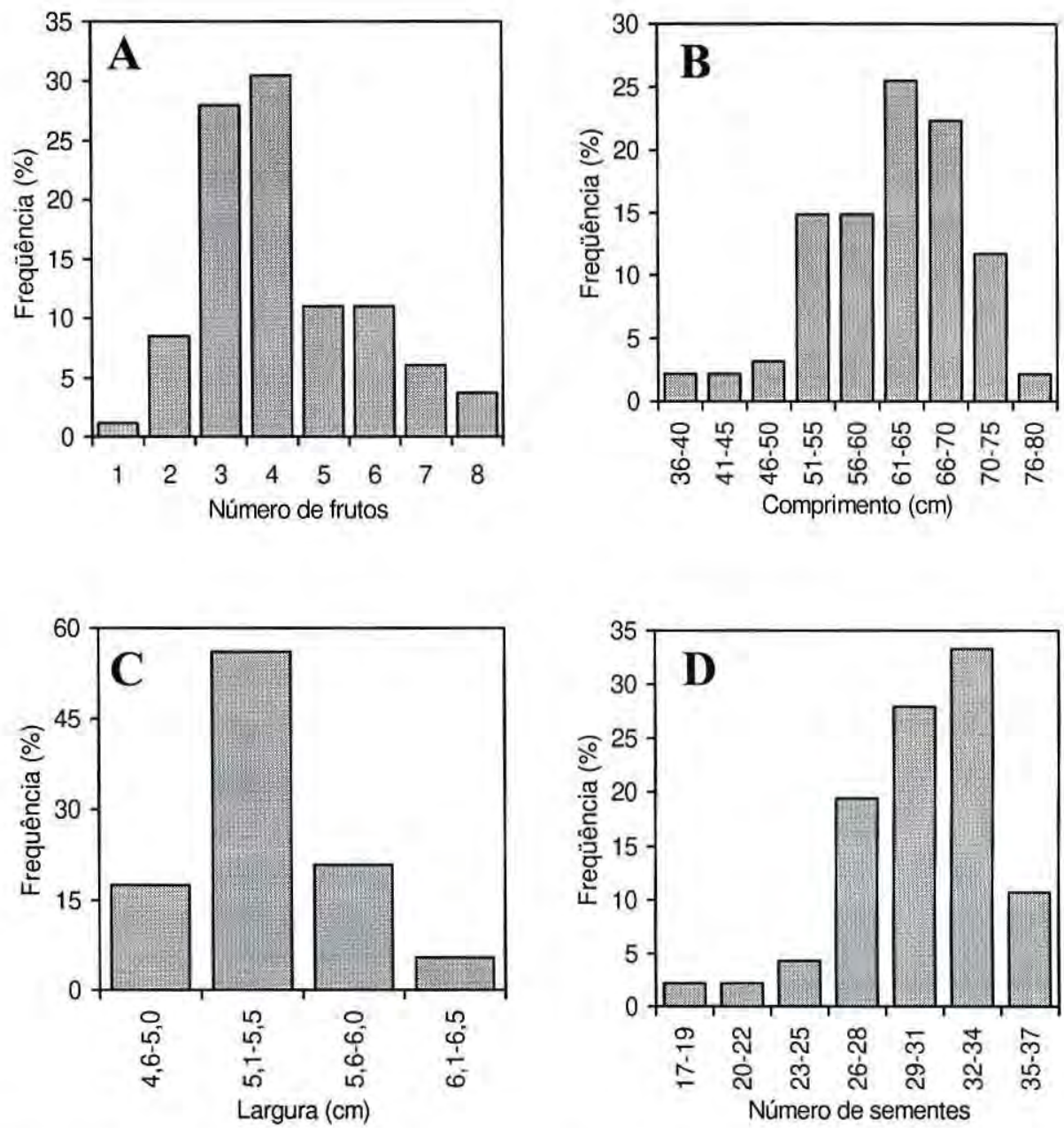

Figura 1. A. Histograma referente ao número de frutos por inflorescência em $P$. nitida; B. comprimento de frutos; C. largura de frutos; D. número de sementes por fruto.

sementes permaneceram com os tegumentos duros, após submetidas a esses respectivos tratamentos (Tab. 1). Resultados semelhantes foram obtidos por Grus et al. (1984), em Caesalpinia leiostachya e Cassia javanica, e por Eschiapati-Ferreira \& Perez (1997), em Senna macranthera. Entretanto, Ribas et al. (1996) e Martins Netto (1994) mostraram que a utilização desse tratamento propicia germinação de $96 \%$ e $64 \%$ em sementes de Mimosa bimucronata e Ochroma pyramidale, respectivamente. Os autores observaram também que o tempo de imersão das sementes na água quente não influenciou na germinação, porém, Grus et al. (1984) afirmam que a exposição de sementes a esse 

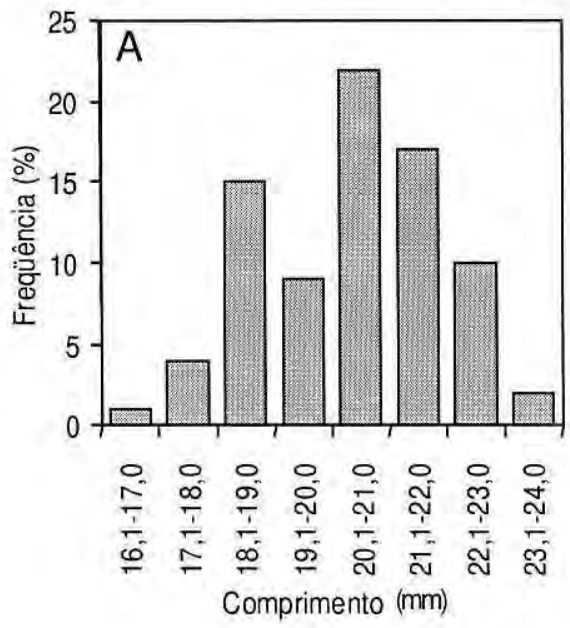
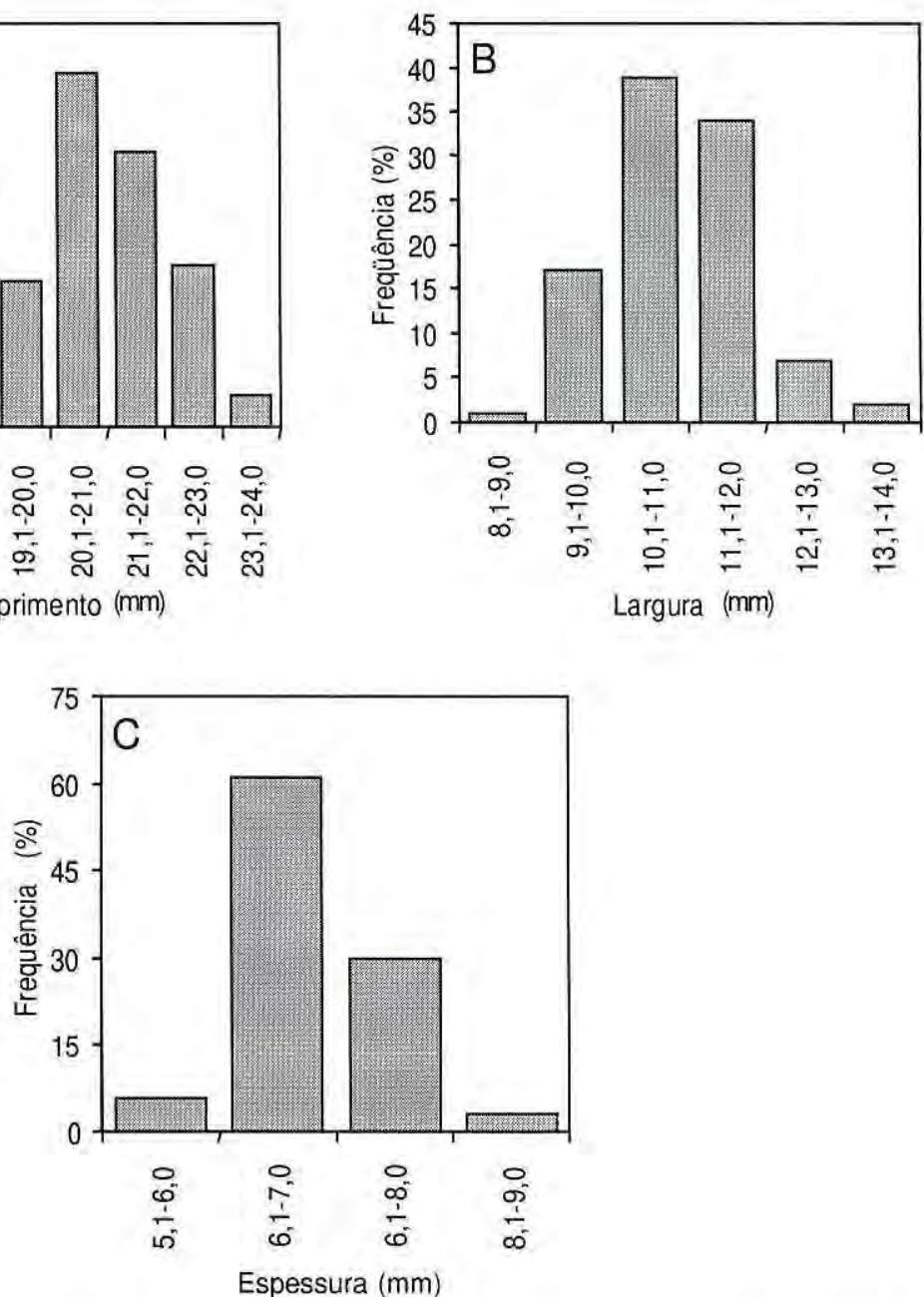

Figura 2. A: Histograma referente ao comprimento de sementes em $P$. nitida; B: largura de sementes; C.espessura de sementes.

tratamento pode causar danos ao embrião, reduzindo a germinação, ou causando a sua morte. (Perez \& Prado, 1993).

A escarificação mecânica em esmeril elétrico teve efeito satisfatório na germinação das sementes e aquelas tratadas com fungicidas apresentaram germinação superior às sementes não tratadas (Figs $3 \mathrm{~A}$ e $\mathrm{B}$ ), fato também comprovado por Gruz et al. (1984), Souza \& Varela (1989) e Martins et al. (1992) em sementes de $C$. leiostachya, Enterolobium schomburgkii e Mimosa caesalpiniaefolia, respectivamente. Entretanto, a utilização desse método pode acarretar maior contaminação das sementes por fungos (Grus et al., 1984). 
Tabela 1. Percentagem de sementes duras e mortas e de plântulas anormais em $P$. nitida.

\begin{tabular}{lccc}
\hline Tratamento & $\begin{array}{c}\text { Sementes duras } \\
(\%)\end{array}$ & $\begin{array}{c}\text { Sementes mortas } \\
(\%)\end{array}$ & $\begin{array}{c}\text { Plântulas anormais } \\
(\%)\end{array}$ \\
\hline Testemunha & $82,0 \mathrm{a}$ & $14,0 \mathrm{~b}$ & $1,5 \mathrm{~b}$ \\
Escarificaçắo mecânica - fungicida & $*$ & $30,5 \mathrm{a}$ & $19,5 \mathrm{a}$ \\
Escarificação mecânica + fungicida & $*$ & $20,0 \mathrm{ab}$ & $7,5 \mathrm{~b}$ \\
Imersão em água a $800 \mathrm{C}$ & $70,0 \mathrm{~b}$ & $17,0 \mathrm{ab}$ & $3,0 \mathrm{~b}$ \\
Imersăo em água a $1000 \mathrm{C}$ & $64,0 \mathrm{~b}$ & $30,5 \mathrm{a}$ & $3,0 \mathrm{~b}$ \\
Imersão em H2SO4 por 10 minutos & $3,0 \mathrm{C}$ & $13,0 \mathrm{~b}$ & $4,0 \mathrm{~b}$ \\
Imersão em H2SO4 por 20 minutos & $*$ & $14,5 \mathrm{~b}$ & $3,0 \mathrm{~b}$ \\
Imersão em H2SO4 por 40 minutos & $*$ & $16,5 \mathrm{ab}$ & $3,0 \mathrm{~b}$ \\
Imersăo em H2SO4 por 80 minutos & $*$ & $21,5 \mathrm{ab}$ & $4,0 \mathrm{~b}$ \\
\hline
\end{tabular}

Médias seguidas da mesma letra, na coluna, não diferem estatisticamente pelo teste de Tukey $(P>0,05)$.

* Médias omitidas da análise de variância por serem iguais a zero.

Os tratamentos com ácido sulfúrico estiveram entre os mais eficientes na superação da dormência. Sementes imersas por 10 e 40 minutos tiveram aumento significativo na germinação durante as avaliações (Figs 4A e B), o que não ocorreu nos tempos de 20 e 80 minutos de imersão, que, após a primeira avaliação, com germinação superior a $80 \%$, apresentou pouco incremento (Fig. 4C). Sementes imersas em ácido sulfúrico durante 20 e 80 minutos apresentaram alta percentagem de germinação já aos dez dias após a semeadura, com incremento pequeno nas demais avaliações. Souza \& Varela (1989), em sementes de $E$. schomburgkii tratadas com ácido sulfúrico por dois, cinco, dez e vinte, minutos obtiveram germinação supe- rior ao observado na espécie em estudo. Observaram também que o tempo de imersão das sementes não influenciou na sua germinação, e que, após nove dias, houve pouca alteração na percentagem de germinação. $\mathrm{O}$ ácido sulfúrico, como tratamento para superação da dormência em leguminosas, tem sido reconhecido como um dos agentes mais eficientes em várias espécies (Martins et al., 1992; Cruz et al., 1995; Ribas et al., 1996; EschiapatiFerreira \& Perez, 1997). A eficiência do ácido sulfúrico na superação da dormência em sementes está relacionada com a espécie e com o tempo de exposição da semente ao ácido, conforme mostram Martins et al. (1992) em M. caesalpiniaefolia, Cruz et al. (1995) em Leucaena 

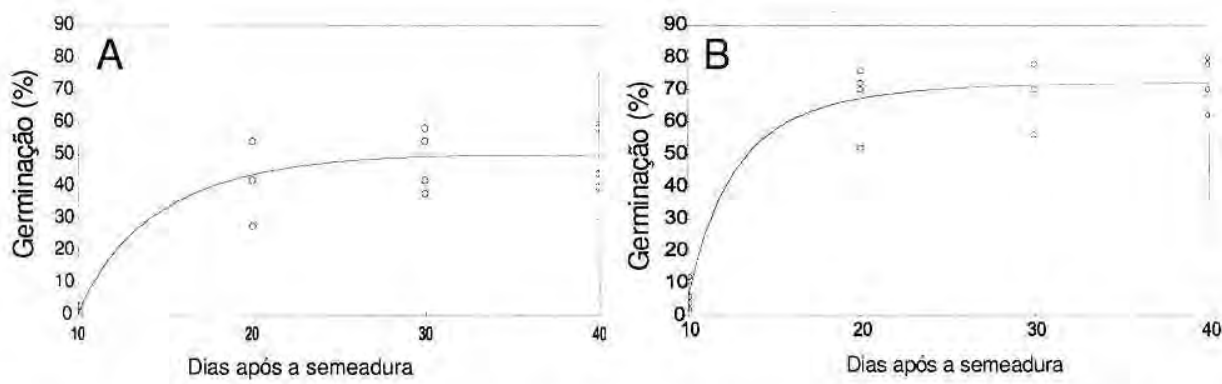

Figura 3. A: Germinação de sementes de $P$. nitida escarificadas em esmeril elétrico, sem aplicação de fungicida, em função do tempo, cuja equação foi $\mathrm{y}=64,57+(-0,28 \mathrm{x})+(-6063,41 /$ $\left.\mathrm{x}^{2}\right), \mathrm{r}^{2}=0,87$; $\mathbf{B}$ : com aplicação de fungicida, cuja equação foi $\mathrm{y}=\left((-7981,47(38,64))+(72,45 \mathrm{x})^{3,67}\right)$ / $\left((38,64) x^{3,67}\right), r^{2}=0,93$.
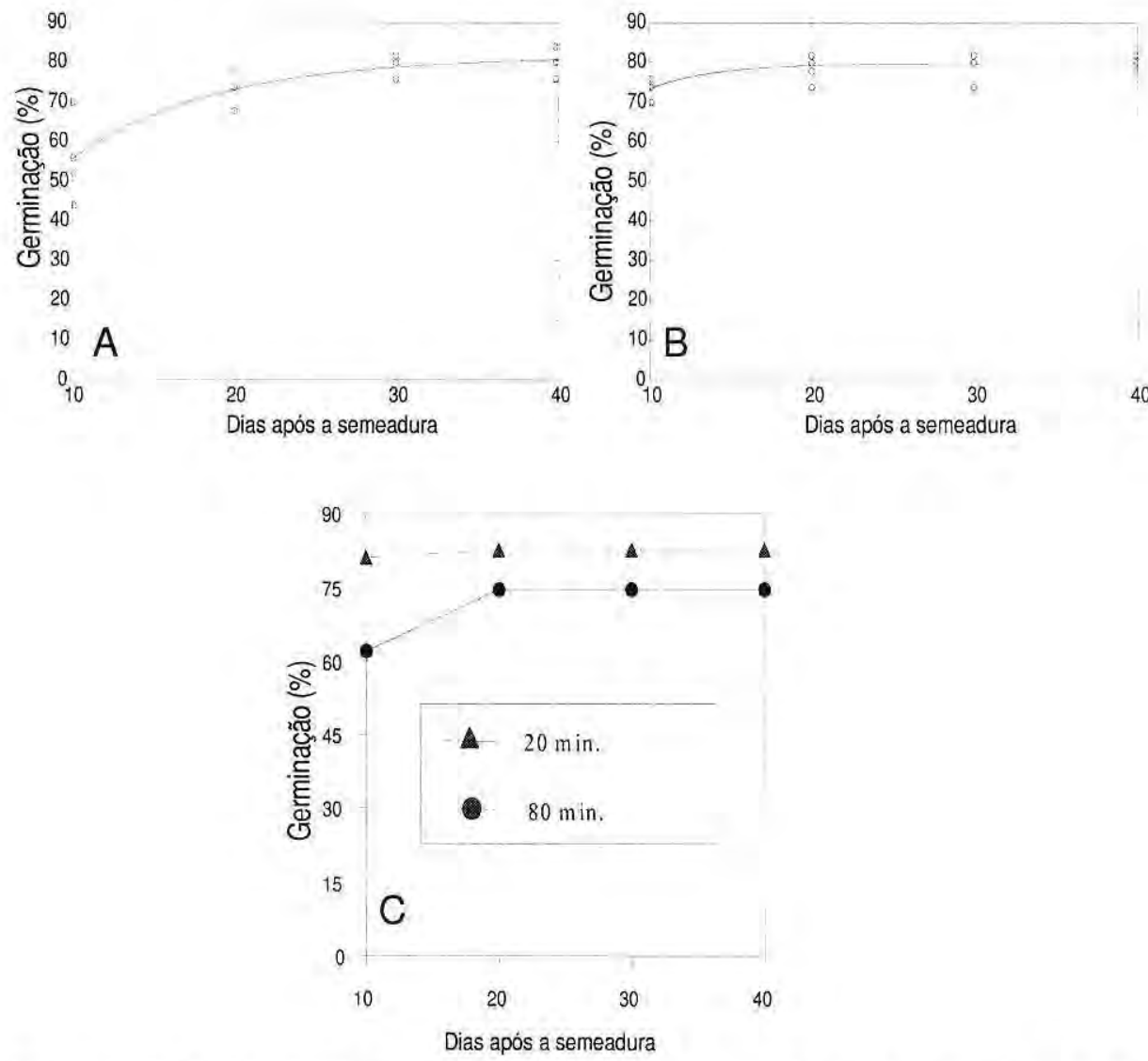

Figura 4. A: Germinação de sementes de $P$. nitida imersas em $\mathrm{H}_{2} \mathrm{SO}_{4}$ por 10 minutos, em função do tempo, cuja equação foi $y=81,43(1-(\exp (-0,11 \mathrm{x}))), \mathrm{r}^{2}=0,77 ; \mathbf{B}: 40$ minutos, cuja equação foi $\mathrm{y}=79,72(1-(\exp (-0,25 \mathrm{x}))), \mathrm{r}^{2}=0,50 ;$ C. Efeito da escarificação de sementes de $P$. nitida em $\mathrm{H}_{2} \mathrm{SO}_{4}$ por 20 e 80 minutos. 
leucocephala e Eira et al. (1993), em Enterolobium contortisiliquum.

Para as percentagens de sementes duras e mortas e a percentagem de plântulas anormais, foi registrada diferença $(\mathrm{P}<0,05)$ entre tratamentos (Tab. 1). O uso da escarificação mecânica com e sem a aplicação de fungicida e com ácido sulfúrico constituiram-se em tratamentos eficientes, reduzindo a percentagem de sementes duras para zero, com exceção do tratamento envolvendo a escarificação ácida durante 10 minutos, em que pequena proporção de sementes ainda permaneceram com o tegumento impermeável à água (Tab. 1). Não obstante, a eficiência desses tratamentos em reduzir a percentagem de sementes duras, em alguns casos os tratamentos foram excessivamente drásticos, provocando maior percentagem de sementes mortas em relação ao tratamento testemunha.

No caso da escarificação mecânica em esmeril elétrico, particularmente quando as sementes foram semeadas sem a aplicação de fungicida, a percentagem de sementes mortas foi duas vezes superior à observada no tratamento em que as sementes foram semeadas sem tratamento prévio para superação da dormência. Tal fato foi decorrente de que a escarificação foi profunda, em muitas sementes, expondo parte dos tecidos cotiledonares, o que favoreceu a infecção por fungos. Nesse caso, a percentagem de plântulas anormais também foi maior. A imersão em água fervente, além de não superar a dormência mostrou-se altamente prejudicial, pois induziu, também, maior percentagem de sementes mortas.

\section{CONCLUSÕES}

Conclui-se que sementes de $P$. nitida apresentam dormência devido à impermeabilidade do tegumento à água, o que torna necessária a sua escarificação para se obter elevada percentagem de germinação. Tratamentos com ácido sulfúrico e escarificação mecânica em esmeril elétrico + fungicida constituem-se métodos eficientes para superação da dormência, sendo que o uso de ácido sulfúrico durante 20 minutos resulta na obtenção de alta percentagem de germinação, em menor tempo

\section{AGRADECIMENTOS}

Ao Dr. Moacyr Bernardino Dias Filho, pelo auxilio nas análises estatisticas.

\section{Bibliografia citada}

Alencar, J. da C.; Magalhães, L.M.S. 1979. Poder germinativo de sementes de doze espécies florestais da regiào de Manaus. Acta Amazonica, 9(3):411-418.

Ahrens, W.H.; Cox, D.J.; Budhwar, G. 1990. Use of the arcsin and square rot transformation for subjectively determined percentage data. Weed Science, 38(5):452458.

Barbosa, A.P.; Vastano Jr., B.; Varela, V.P. 1984. Tratamentos pré-germinativos de sementes de espécies florestais amazônicas. II. Visgueiro (Parkia pendula Benth. Leguminosae - Mimosoideae). Acta Amazonica, 14(1-2):280-288.

Baskin, C.C.; Baskin, J.M. 1998. Seeds: ecol- 
ogy, biogeography, and evolution of dormancy germination. Academic Press, London. $666 \mathrm{p}$.

Brasil. 1992. Regras para análise de sementes. Ministério da Agricultura e Reforma Agrária, Brasilia. 365p.

Carpanezzi, A.A.; Marques, L.C.T. 1981. Germinação de sementes de jutaí-açu (Hymenaea courbaril L.) e de jutai-mirim (H. parvifolia Huber) escarificadas com ácido sulfúrico comercial. EMBRAPACPATU, Circular Técnica, 19. Belém. $15 \mathrm{p}$.

Corrêa, M.P. 1926. Dicionário das plantas úteis do Brasil e das exóticas cultivadas. Vol. I. Imprensa Nacional, Rio de Janeiro. $747 \mathrm{p}$.

Cruz, E.D.; Carvalho, J.E.U. de; Oliveira, R.P. de. 1997. Variabilidade na germinaçào e dormência em sementes de Centrosema pubescens Benth. Pasturas Tropicales, 19(1):37-41.

Cruz, M.S.D.; Perez-Urria, E.; Martin, L.; Avalos, A.; Vicente, C. 1995. Factors affecting germination of Canavalia brasiliensis, Leucaena leucocephala, Clitoria ternatea and Calopogonium mucunoides seeds. Seed Science and Technology, 23(2):447-454.

Duarte, A.P. 1978. Contribuição ao conhecimento da germinação de algumas essências florestais. Rodriguésia, 30(45):439-446.

Eschiapati-Ferreira, M.S.; Perez, S.C.J.G.A. 1997. Tratamentos para superação da dormência de sementes de Senna macranthera (Collad.) Irwin et Barn. (Fabaceae-Caesalpinioideae). Revista Brasileira de Sementes, 19(2):231-237.

Eira, M.T.S.; Freitas, R.W.A.; Mello, C.M.C. 1993. Superação da dormência de sementes de Enterolobium contortisiliquum (Vell.) Morong. Leguminosae. Revista Brasileira de Sementes, 15(2):177-181.

Etejere, E.O.; Fawole, M.O.; Sani, A. 1982. Studies on seed germination of Parkia clapertoniana. Turrialba, 32(2):181-185.

Fenner, M. 1993. Seed ecology. Chapman \& Hall, London. 151p.
Finney, D.J. 1989. Was this in your statistics textbook? V. Transformation of data. Experimental Agriculture, 25(2):165-175.

Grus, V.M.; Demattê, M.E.S.P.; Graziano, T.T. 1984. Germinação de sementes de pauferro e cássia-javanesa submetidas a tratamentos para quebra de dormência. Revista Brasileira de Sementes, 6(2):2935 .

Hopkins, H.C.F. 1986. Parkia (Leguminosae: Mimosoideae). In: Flora Neotrópica, 43, New York Botanical Garden, New York. $124 \mathrm{p}$.

IBDF. 1987. Padronização da nomenclatura comercial brasileira das madeiras tropicais amazônicas. Instituto Brasileiro de Desenvolvimento Florestal, Brasília. $85 \mathrm{p}$.

Knowles, O.H.; Parrotta, J.A. 1995. Amazonian forest restoration: an innovative system for native species selection based on phenological data and field performance. Commonwealth Forestry Review, $74(3): 230-243$.

Martins, C.C.; Carvalho, N.M. de; Oliveira, A.P. de. 1992. Quebra de dormência de sementes de sabiá (Mimosa caesalpiniaefolia Benth.). Revista Brasileira de Sementes, 14(1):5-8.

Martins Netto, D.A. 1994. Germinação de sementes de pau-de-balsa (Ochroma pyramidale (Cav.) Urb.) - Bombacaceae. Revista Brasileira de Sementes, 16(2):159-162.

Minitab. 1993. Reference Manual: Release 9 for Windows. Minitab, State College, PA. Inc.

Perez, S.C.J.G. de A.; Prado, C.H.B. de A. 1993. Efeitos de diferentes tratamentos pré-germinativos e da concentração de aluminio no processo germinativo de sementes de Copaifera langsdorfii Desf. Revista Brasileira de Sementes, 15(1):115118.

Ribas, L.L.F.; Fossati, L.C.; Nogueira, A.C. 1996. Superação da dormência de sementes de Mimosa bimucronata (DC.) O. Kuntze (Maricá). Revista Brasileira de Sementes, 18(1):98-101. 
Rolston, M.P. 1978. Water impermeable seed dormancy. The Botanical Review, 44(3):365-396.

Souza, S.G.A. de; Varela, V.P. 1989. Tratamentos pré-germinativos em sementes de faveira orelha-de-macaco (Enterolobium schomburgkii Benth.). Acta Amazonica, 19(único):19-26.

Statsoft. 1994. Statistica for Windows. General conventions and statistics. Vol, I. StatSoft, Tulsa, OK. Inc.

Varela, V.P.; Aquino, P.A.N. de; Azevedo, C.P. de. 1986/1987. Tratamentos prégerminativos em sementes de espécies florestais da Amazônia. III. Faveira-araratucupi (Parkia decussata Ducke) Leguminosae. Acta Amazonica, 16/ 17(único):557-562.

Zar, J.H. 1996. Biostatistical analysis. 3.ed. Prentice Hall, New Jersey. 988 p. 